\title{
University of New Hampshire

\section{Steyer Spends the Most, but Only Yang and Gabbard Focus Facebook Advertising on New Hampshire}

\author{
Jordan Hensley
}

$\mathrm{D}$ emocratic presidential candidates care a lot about the New Hampshire primary, but they only targeted 2.6 percent of their total Facebook ad spending at New Hampshire in the last quarter of 2019 according to data compiled by Booster Media, Inc. Among Democratic Primary candidates, Tom Steyer easily spent the most over this time period with $\$ 445,873$ spent on Facebook ads targeted at Granite Staters-but that amounted to less than 5 percent of his total Facebook spending. Andrew Yang and Tulsi Gabbard were more focused on the state with 16 percent and 24 percent of their spending aimed at New Hampshire, but in dollar terms $(\$ 107,401$ and $\$ 72,588)$ they trailed both Steyer and Pete Buttigieg $(\$ 143,571)$. Booster Media also provided data on Bernie Sanders and Donald Trump, both of whom are spending less than one percent of their total Facebook ad budget in New Hampshire. These data do not mean any of these, or the other, candidates are not focused on New Hampshire, but it may suggest that they are utilizing methods other than Facebook ads to reach Granite State voters.

\section{Q4 FACEBOOK AD SPENDING IN NEW HAMPSHIRE-TOP FIVE CANDIDATES}

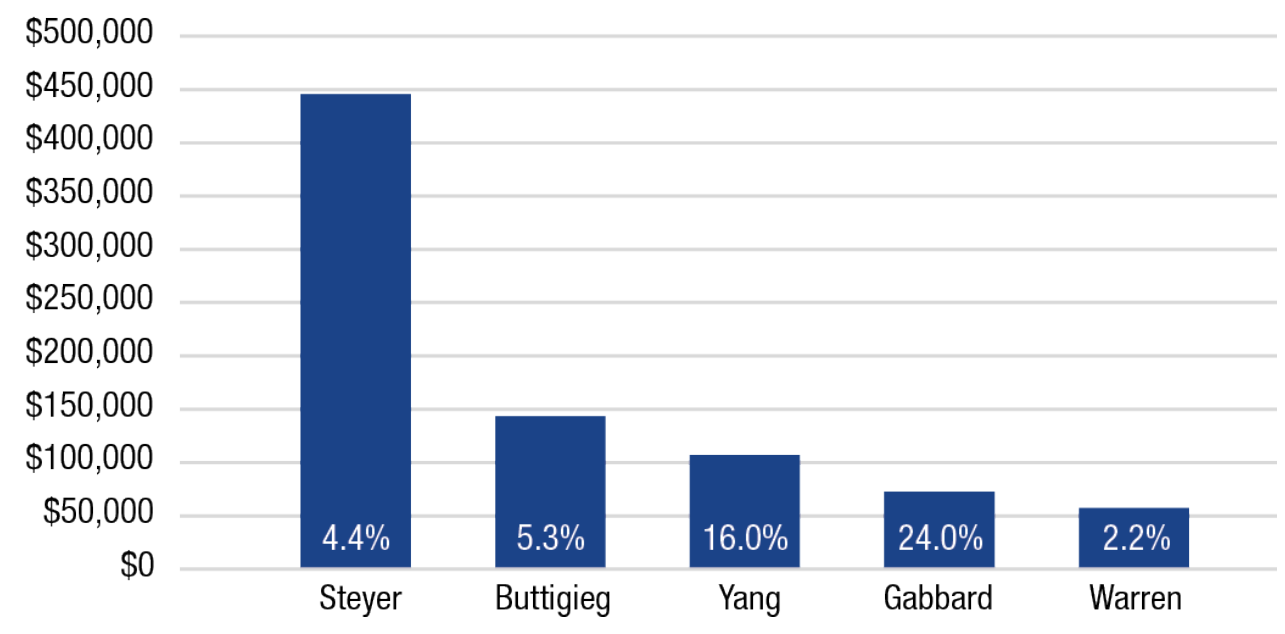

Note: The above chart shows the five candidates who are spending the most on Facebook ads in New Hampshire. The percentages indicate how much of their total Facebook ad budget they are spending targeting Granite Staters. Source: Facebook ad data provided by Booster.

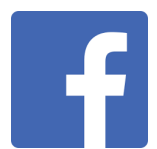

Democratic candidates are only spending a fraction of their overall Facebook ad budgets targeting Granite Staters.
Huddleston Hall • 73 Main Street • Durham, NH 03824 carsey.unh.edu $\bullet 603.862 .2821$
TTY USERS: DIAL 7-1-1 OR

1-800-735-2964 (RELAY N.H.) 